\title{
SAÚDE MENTAL E ECONOMIA SOLIDÁRIA: CARTOGRAFIAS DO SEU DISCURSO POLÍTICO
}

\author{
SALUD MENTAL Y ECONOMÍA SOLIDARIA: CARTOGRAFÍA SU \\ DISCURSO POLÍTICO \\ MENTAL HEALTH AND SOLIDARITY ECONOMY: CARTOGRAPHY ITS \\ POLITICAL DISCOURSE
}

http://dx.doi.org/10.1590/1807-03102015v27n3p700

Eneida Santiago

Universidade Estadual de Londrina, Londrina/PR, Brasil

Silvio Yasui

Universidade Estadual Paulista, Assis/SP, Brasil

\begin{abstract}
RESUMO
O presente artigo se refere à composição do campo discursivo em torno da questão do trabalho, pelo aporte da economia solidária, como estratégia de atenção em saúde mental. Através da cartografia e de alguns operadores analíticos de Foucault (biopolítica, governamentabilidade, normalização), mapeamos a configuração de forças e enfrentamentos que agenciaram a constituição da política pública brasileira de saúde mental e economia solidária. Em nossas análises apontamos uma ambiguidade no conceito trabalho presente nos documentos, a polissemia de expressões utilizadas para designar o trabalhar, um significativo discurso de valorização da inserção, via emprego, no mercado formal de trabalho, e a insuficiência de estratégias políticas e legais que deem sustentabilidade material às experiências práticas. Em contrapartida, destacamos como a economia solidária na saúde mental também diferencia-se ao valorizar o trabalho como possibilidade de estar no social de forma mais integral que as simplificadas relações utilitárias e normalizantes que o capitalismo fortemente investe.
\end{abstract}

Palavras-chave: saúde mental; política pública, economia solidária; saúde coletiva.

\section{RESUMEN}

Este artículo se refiere a la composición de campo discursivo en torno a la cuestión del trabajo, la contribución de la economía social, como estrategia de atención a la salud mental. A través de la cartografía y algunos operadores de análisis de Foucault (biopolítica, gubernamentalidad, la normalización), estudiamos la configuración de fuerzas y enfrentamientos que agenciaram la formación de la política pública brasileña mentales salud y la economía solidaria. En nuestros análisis señalar una ambigüedad en este concepto de trabajo en los documentos, la polisemia de los términos utilizados para describir el trabajo, una inserción significativa mejora del habla, a través de empleo en el mercado laboral formal, y la falta de estrategias políticas y jurídicas que dan materiales de sostenibilidad a las experiencias prácticas. Por otro lado, se destaca cómo la economía solidaria en salud mental también es diferente a valorar el trabajo como una posibilidad para ser social de manera más integral que las relaciones utilitarias simplificados y la normalización de que el capitalismo en gran medida invierte.

Palabras clave: salud mental; política pública; economía solidaria; salud colectiva.

\begin{abstract}
This article refers to the composition of the discursive field around the labor question, of social economy contribution, as extended by the mental health strategy. Through mapping and some analytical operators of Foucault (biopolitics, governmentality, normalization), we mapped the configuration of forces and clashes that elaborated the formation of Brazilian public policy regarding mental health and solidarity economy. In our analysis we point out an ambiguity presented in the documents regarding this work concept, the polysemy of terms and expressions used to designate labor activity, a significant discourse on the appreciation of insertion in the formal labor market via employment, and the lack of political and legal strategies that give sustainability to practical experiences. However, we highlight how the solidarity economy in mental health also differs by valuing work as a possibility of being social in a more integral way than the utilitarian and normative relations that capitalism heavily invests.
\end{abstract}

Keywords: mental health; public policy; solidarity economy; collective health. 


\section{Definindo campo e objeto}

Este artigo se refere à composição de um campo discursivo em torno da questão do trabalho, pelo aporte da economia solidária (ECOSOL), como estratégia ampliada de atenção em saúde mental. Através da cartografia, mapeamos a configuração de um campo de forças e enfrentamentos que, articulados, agenciaram a constituição de uma política pública brasileira de saúde mental e economia solidária. Compreendemos que, na emergência de acontecimentos, são formadas relações de poder que constituem forças e produzem ações e indivíduos sujeitados e úteis, ao mesmo tempo que incitam movimentos, articulações, resistências e enfrentamentos (Foucault, 1986). No enlace entre saúde mental e economia solidária, o domínio de forças e confrontos se fez, e se faz, por movimentos sociais vários, instâncias institucionais, discursos governamentais e políticos que colocam em questionamento a potência de ruptura que $\mathrm{o}$ enlace saúde mental - economia solidária, e suas políticas públicas e documentos oficiais, tem para possibilitar a construção de relações de trabalho que sejam produtoras de vida, e não reprodutoras de novas clausuras (do universo da loucura, para o submundo do mercado de trabalho).

Por meio de diálogos firmados com alguns operadores analíticos de Michel Foucault, inicialmente, discutimos as posições da ECOSOL enquanto proposta de constituir formas mais éticas, justas e includentes, de viver em sociedade. Após isso, apreendemos as acepções da política pública brasileira de saúde mental e economia solidária em suas proposições, conceituações, discursos e sentidos presentes e ausentes, bem como em seus sentidos agenciados. Finalizamos, analisando os conceitos de trabalho que alimentaram os agenciamentos no campo discurso.

A cartografia como escolha metodológica na jornada aqui realizada foi feita por ser ela atenta à complexidade e pluralidade do campo sobre o qual nos debruçamos. A cartografia não é exatamente um método em si, mas uma discussão metodológica que se atualiza na medida em que os caminhos e os encontros do cartógrafo com os territórios estudados acontecem. Encontros e afetações que, mesmo não sendo a finalidade do processo sucessivo de aproximação e distanciamento, são parte integrante do movimento de conhecer. A composição das cartografias, como nos mapas emprestados da geografia, são desenhos de paisagens que se fazem ao mesmo tempo que se transformam. Os desenhos são abertos, assim como são $\underline{\text { os }}$ mundos que representam, não sendo, nem pretendendo ser, estáticos, fechados ou definitivos. Segundo Rol- nik (1989, p. 15), as "paisagens psicossociais também são cartografáveis". Para ela, a tarefa de cartografar pressupõe a valorização do processo formativo e das histórias que constroem realidades, mas também dos afetos mobilizados e dos sentidos produzidos a partir das mudanças subjetivas que o contato com a vida social e com o cotidiano dispara.

Desta forma, a cartografia "é uma prática de pesquisa que acompanha o processo de produção de subjetividade" (Rolnik, 1989, p. 21). Neste artigo, as cartografias foram construídas exclusivamente a partir de nossos contatos e das experimentações de leituras e análises de documentos vários e políticas públicas, sendo que as reflexões que realizamos são a possibilidade de uma outra paisagem, de novos territórios de expressões e visibilidades da ECOSOL em sua articulação com a saúde mental. Dessa maneira, as cartografias que aqui traçamos dão expressividade aos campos de lutas e enfrentamentos em torno da relação saúde mental-ECOSOL, seus movimentos, acareações e agenciamentos discursivos. Apesar de necessário, não é nosso objetivo neste artigo problematizarmos de forma mais atenta e demorada os desenrolares e efeitos práticos e cotidianos da política pública de saúde mental e economia solidária, mas sim buscamos analisar continuidades e descontinuidades das práticas de poder, subjetivação de modos de conceber e discursar sobre o trabalhar, pelo aporte da economia solidária, de usuários da saúde mental.

\section{Construindo a problemática}

A partir dos anos de 1970, iniciou-se no Brasil um processo de mudança paradigmática do modelo de atenção em saúde mental, denominado Reforma Psiquiátrica. $\mathrm{O}$ modo antes hegemônico era marcado pela segregação social e política dos indivíduos considerados adoecidos, assim como por uma assistência asilar hospitalocêntrica, em que a instituição manicomial, em suas construções arquitetônica e ideológica, era o espaço privilegiado de exame, tratamento e enquadramento normalizante do louco e da loucura (Amarante, 2000, Saraceno, 2001). Inicialmente, nos espaços manicomiais, e com a Reforma Psiquiátrica também nos contextos extra-hospitalares e comunitários, o trabalho e o trabalhar como eixo norteador de práticas de atenção e cuidado em Saúde Mental se constituiu a partir de muitos sentidos, dando conta de objetivos vários, como anteriormente discutimos em outros escritos (Santiago \& Yasui, 2011; 2013). Recentemente, desde os anos 2000, o intercâmbio trabalho - saúde mental ganhou em composição com a sustentação da perspectiva da economia solidária. 
Apesar de experiências práticas anteriores, a articulação entre saúde mental e ECOSOL no processo da Reforma Psiquiátrica se inseriu como alternativa politicamente orientada e possível com a determinação da Lei 10.216/2001, que orienta que a construção da atenção às pessoas em sofrimento psíquico deveria ocorrer através de ações que objetivassem a reinserção e o fortalecimento da contratualidade e dos laços sociais, por meio do resgate e do exercício da autonomia, da cidadania, dos vínculos familiares, do acesso à cidade, ao trabalho e aos espaços e processos coletivos que a vida em comunidade poderia propiciar. É pelo viés da Reforma Psiquiátrica que a ECOSOL, como escolha teórica, metodológica e ética de configuração das relações de vida e trabalho, se aproximou das conjunturas da saúde mental recentemente.

Paul Singer localiza o nascimento da ECOSOL como sendo "pouco depois do capitalismo industrial, como reação ao espantoso empobrecimento dos artesãos provocado pela difusão das máquinas e da organização fabril da produção" (Singer, 2002, p. 24). Desse modo, a ECOSOL é uma proposta diferenciada de pensar e realizar o trabalho, pautada por princípios de uma sociedade mais solidária, em que o trabalhar está presente, mas também, as necessidades materiais e imateriais, como a qualidade de vida, o desenvolvimento pessoal, o acesso ao consumo, entre outros. Os princípios da ECOSOL são cooperação, solidariedade, autogestão, sustentação econômica e sustentabilidade ambiental (Singer, 2002). Contrapondo-se à competição, à hierarquização e ao empobrecimento das relações sociais e produtivas do capitalismo, a ECOSOL valoriza a confecção de produtos e vínculos mais éticos, justos e permeados de sentidos.

O movimento da ECOSOL, que vem ocorrendo em intensidade gradual nos últimos 20 anos, marca a expressãodaação pública de diversos segmentos sociais, tais como gestores governamentais, movimentos sociais populares, universidades, dentre outros. Embora as várias iniciativas de apoio ${ }^{1}$, o movimento ganhou maior notoriedade a partir das discussões e articulações ocorridas no fim da década de 1990 entre instituições e entidades de suporte às experiências coletivas de trabalho, produção e comercialização. Em termos de sua organicidade, o movimento se alimentou da criação do Fórum Social Mundial, em 2001, e do Fórum Brasileiro de Economia Solidária (FBES) em 2003 (que atualmente conta também com edições estaduais e microrregionais), da criação, também em 2003, da Secretaria Nacional de Economia Solidária (SENAES), vinculada ao Ministério do Trabalho e Emprego (MTE), que contribuiu para a criação de secretarias, departamentos e gerências de ECOSOL em diversos municípios e estados brasileiros, e, por fim, da constituição do Conselho Nacional de Economia Solidária, implantado em 2006, após a I Conferência Nacional de Economia Solidária, que tem se constituído em um importante espaço de discussão e construção de políticas públicas.

Enquanto movimentos sociais, políticos e práticos em curso na sociedade brasileira, a Reforma Psiquiátrica e a ECOSOL são igualmente processos coletivos que objetivam acontecer em contextos, por vezes, enclausurados em institucionalizações de processos e relações de trabalho e de atenção e cuidados em saúde mental. Por isso, na atualidade, discutir a enunciação da atenção em saúde mental confeccionada na economia solidária é tão importante quanto problematizar os processos de trabalhar produzidos pela saúde mental, como já realizamos em outra oportunidade (Santiago \& Yasui, 2011).

\section{A economia solidária como política pública: a produção de contratualidade social}

A estratégia da inclusão social pelo trabalho na saúde mental, uma iniciativa do Ministério da Saúde, está fundamentada nas Leis n. 9.867/1999 e n. $10.216 / 2001$. No entanto, o fundamento da inclusão social pela via, especificamente, da economia solidária foi regulamentado somente em 2005 pela Portaria Interministerial n. 353/2005.

No âmbito da ECOSOL no Brasil, as décadas de 1980 e 1990 presenciaram a experimentação de seus primeiros exercícios práticos. O contexto de redemocratização e efervescência social e política foi o impulsionador da criação e atuação de variados movimentos sociais urbanos e rurais e do sindicalismo autônomo e independente. Todavia, ao mesmo tempo, se constituía uma conjuntura inicial de crise econômica marcada por privatizações, desemprego, flexibilização dos direitos trabalhistas, inflação em alta e aumento dos índices de pobreza, que se acirrariam nos anos seguintes acompanhados por sentimentos de desamparo daqueles que viviam do trabalho. Foi diante da impossibilidade de construção de um projeto social e político que aproximasse os coletivos e superasse estruturas injustas e perversas do universo do trabalho que tomaram força experiências práticas autogestionárias e solidárias de geração de trabalho e renda em atividades de recuperações de empresas, mutirões habitacionais e criações de Cooperativas Populares e Grupos Comunitários de Trabalho. Em 2003, a Lei Federal n. 10.683 criou a SENAES no âmbito do MTE, momento em que a ECOSOL se tornou política pública no Governo Federal brasileiro. 
No ordenamento jurídico brasileiro atual, não há uma definição de economia solidária. Conceitualmente, se compreende como sendo o conjunto de atividades econômicas de produção, distribuição, consumo, poupança e crédito, organizadas sob a forma autogestionária e solidária (Portaria Interministerial 353, 2005). Como processo de anunciação coletiva, na economia solidária, o processo e o produto do trabalho não são dissociados do sujeito trabalhador, que é constituído como parte potente e visível da relação criativa e criadora que constrói com a experiência de trabalho; assim, o trabalhador é o protagonista do processo.

A partir da criação da SENAES, inicia-se para o Estado brasileiro a assunção de uma nova realidade do trabalho, assim como de sua conceituação. Isso porque, em termos de política pública, a geração de trabalho e renda com o aporte da ECOSOL abandona o foco exclusivamente no emprego formal. Também com a SENAES, práticas e programas isolados e desarticulados de geração de trabalho e renda ganham maior suporte legal e técnico e assumem (não ignorando ou cimentando em uma unidade frágil) a fragmentação e a heterogeneidade do mundo do trabalho, inclusive se atentando para as formas e os laços informais de trabalho (Barbosa, 2007). No campo das relações de trabalho contemporaneamente construídas, analisamos que a identificação de suas heterogeneidades pelas políticas públicas representa a possibilidade do início de um necessário processo do Estado e da sociedade brasileira para pensar, vivenciar, sentir e estar na experiência trabalho de formas distintas das até então exercidas e mercadologicamente valorizadas. Neste contexto, a ECOSOL, como eixo da política pública de inclusão social pelo trabalho, se configura como uma reação à exclusão produzida na lógica capitalista.

A constituição da SENAES $^{2}$, bem como os esforços empenhados no estabelecimento de políticas públicas, é caminho para que a economia solidária componha a agenda política brasileira, garantindo que ela permaneça como política de Estado e não só como política de Governo. Criando, ou se dedicando a criar, uma outra forma de governamento da questão do trabalho, o Estado também faz uso de uma estratégia de sustentação e exercício de seu poder em um contexto em que a precarização das atividades e do mercado de trabalho é cada vez maior.

Avaliamos que, como tática, cabe ao Estado moldar sua prática governamental à realidade do trabalho que se transforma, ele faz uso de um dispositivo de segurança de inflexão e direcionamento de política estatal. Mas por que o Estado faria isso? Foucault (2008a) já sinalizou que o Estado, em essência, governa para si, gerindo seu poder para gerir sua existência. Mantendo-se assertivo às mazelas do trabalho e dos trabalhadores, o Estado está investindo em uma majoração da qualidade de vida da população, na heteronomia de um fazer viver, em consonância com o que o mesmo Foucault (2008a) denomina biopolítica, ou seja, práticas de governança que gerem populações inteiras buscando manter e ampliar a vida, um fazer viver de reconfiguração da administração dos imprevistos, que também é de gestão dos riscos, e em nosso contexto de discussão, riscos do mundo do trabalho.

Mesmo com a identificação de fatores como os acima citados, não podemos ignorar que a construção de projetos de geração de trabalho e renda pelo aporte da economia solidária é uma oportunidade para o estabelecimento de atividades de trabalho que podem ser canais para a construção de contratualidades sociais, isto é, atividades em que são disponibilizados recursos materiais e imateriais para trocas sociais e, por conseguinte, para a cidadania social plena de sujeitos trabalhadores, que podem assim exercer o papel de protagonistas de seu próprio fazer e de sua própria história.

No campo da saúde mental, a economia solidária representa também a possibilidade do fortalecimento de uma luta por um outro olhar sobre a loucura: aquele em que o sofrimento psíquico não sustenta (e afirma por si só) o afastamento do sujeito adoecido do corpo social.

\section{Saúde mental e economia solidária: a produção da intersetorialidade}

A partir do final dos anos de 1990, as áreas de saúde mental e de ECOSOL (movimentos sociais, militantes e trabalhadores excluídos do mercado formal, dentre outros), passaram sistematicamente a empenhar esforços para a construção de pontes políticas, sociais e práticas, para que os sujeitos em sofrimento psíquico pudessem, de forma autêntica, ampla e integral, acessar e exercer sua cidadania no tecido social, por meio (mas não só) da experiência trabalho. Nesse processo, as experimentações práticas antecederam as prerrogativas políticas, sofrendo com a falta de sustentabilidade (material e econômica, dentre outras) que as políticas públicas poderiam suprimir, tais como as iniciativas apoiadas pela Incubadora Tecnológica de Cooperativas Populares (ITCP), localizada no estado do Rio de Janeiro (Lima, Silva, Falchetti, \& Cruz, 2013).

O processo de composição da parceria entre saúde mental e economia solidária tem o ano de 2001 
como um marco. Nesse ano, a OMS (Organização Mundial de Saúde) o declarou como sendo o ano da Saúde Mental, instituindo o tema "Cuidar, sim. Excluir, não", que pouco eco fez no então contexto de exclusão e abandono social dos sujeitos em sofrimento psíquico. Foi a urgente necessidade de uma rede de suporte e efetividade de proteção e reinserção social que, no mesmo ano, também marcou o panorama da III Conferência Nacional de Saúde Mental (CNSM), realizada em Brasília, em dezembro, assumindo para o evento o mesmo tema utilizado pela OMS. Quando a III CNSM foi realizada, havia menos de um ano da aprovação da Lei n. 10.216/2001. Assim, as (re)configurações de forças hegemônicas e contra-hegemônicas no universo de atenção e cuidado em saúde mental no Brasil estavam em pleno processo. Nesse contexto, a Conferência representou o fortalecimento da proposta da Reforma Psiquiátrica, ao mesmo tempo que criou espaço para discussões e desdobramentos políticos e práticas sobre as condições de efetivação de uma proposta antimanicomial.

A leitura do relatório da III CNSM permite a identificação do uso da expressão reabilitação psicossocial, em abandono à reinserção social, reinclusão social e trabalho protegido anteriormente presentes nos documentos oficiais. Tal mudança indica um esforço tímido discursivo, mas também político, em romper com a perspectiva adaptativa ao trabalho e restritiva em sua integralidade, que ideariamente se fazia presente em escritos anteriores a 2001, quando focando a relação entre trabalho e saúde mental. Justificamos nossa afirmação de a modificação do termo empregado ser um esforço tímido, porque a troca de palavras como reinserção, reinclusão e trabalho protegido por reabilitação não representa uma significativa amplitude conceitual, pois ainda traz marcadamente a presença do prefixo " $r e$ ", que contempla um sentido de voltar a algo, ou seja, de retorno ao perdido, abandonado, enquanto parâmetro referencial estabelecido. Já a presença da expressão psicossocial, como conceito caro para o movimento da Reforma Psiquiátrca, sustenta a perspectiva de um exercício ampliado da cidadania e do intercâmbio social em cenários variados, que são casa, trabalho e rede social, como sinalizado por Saraceno (2001).

Ainda no ano de 2001, este pode ser identificado como o momento em que a inclusão social pelo trabalho se torna política pública de saúde mental, contemplando dimensões mais complexas e menos institucionalizadas do trabalho enquanto estratégia produtora de vida e de valor. Sendo que, no contexto da saúde mental, as atividades de inclusão social pelo trabalho apresentam as linhas da busca por vagas pelo sistema de cotas em espaços organizacionais, e da atividade coletiva por meio de oficinas, projetos de geração de trabalho e constituição de sistemas cooperativos de trabalho, apesar de estes últimos não se formalizarem como cooperativas sociais conforme caracteriza a Lei 9.867/99, que restringe o trabalho à dimensão de protegido. O resgate e a discussão sobre a lei de 1999, e das cooperativas sociais, somente serão feitos em 2010 na IV Conferência.

Em 2004, a área técnica de Saúde Mental e a SENAES estabeleceram uma aliança com o intuito de fomentar mais objetivamente as experiências de geração de trabalho e renda, constituindo um grupo de trabalho interministerial (instituído pela Portaria Interministerial 353/2005). A intersetorialidade da política pública que se delineia discursivamente indica potencialidade para que outros projetos do viver em coletividade se edifiquem: um outro projeto compreensivo e relacional, que desmonta e ultrapassa o manicômio em seus parâmetros terapêuticos, institucionais e ideológicos; um outro projeto produtivo em que o trabalho e o trabalhar produzem relações, experimentações e também produzem produtos, serviços e distintas relações de consumo; um outro projeto de vida em sociedade, que seja mais inclusivo, ético e solidário.

Dando suporte legislativo e político, e mais uma vez também discursivo, em 2005 a Portaria Interministerial n. 353 instituiu o grupo de trabalho de Saúde Mental e Economia Solidária, composto por representantes de instituições e instâncias diversas das duas áreas, que são desde os Ministérios até redes gestoras e de experiências práticas. A inclusão social pelo trabalho na saúde mental, baseada nos princípios da economia solidária, conforme contemplada pela Portaria, é fruto da parceria entre SENAES e Coordenação Nacional de Saúde Mental. A formulação da proposição de inclusão social pelo trabalho como estabelecido pela Portaria considerou as deliberações da I Oficina Nacional de Experiências de Geração de Renda e Trabalho de Usuários de Serviços de Saúde Mental, realizada em 2004 e da qual participaram iniciativas formais e informais desta área, que foram representadas no evento por técnicos, coordenadores municipais e estaduais, além de usuários. Destacamos como mérito do documento em questão as proposições de articulações entre as ações de saúde mental e economia solidária em suas dimensões e interfaces política, financeira, técnica e prática. Tais asserções são frutos de encontros de processos históricos, sociais e políticos, tanto no campo da ECOSOL quanto da saúde mental. Efetividade e sustentação material e econômica são os sentidos dos discursos que o Grupo Interministerial, segundo a portaria pela qual é instituída, objetivará. Ao mesmo tempo se reco- 
nhece a fragilidade vivenciada pelos empreendimentos e experiências de economia solidária na saúde mental, devido à falta de sustentação teórico-técnica de experiências e processos de incubagem solidária, bem como à dificuldade de manutenção financeira. Ligado ao suporte material, mas para além de um reducionismo diretamente financeiro, há ainda nas linhas do documento a preocupação com o apoio da comercialização dos produtos e serviços frutos dos empreendimentos de geração de trabalho e renda. Significa uma inovação à clareza de que, em qualquer discussão sobre o trabalho, não se devem descolar deste as asserções sobre processos e relações de consumo. A Portaria Interministerial em questão apresenta diretrizes legais para uma política pública intersetorial entre saúde mental e economia solidária, que nos anos seguintes contribuíram para a constituição de dispositivos institucionais, tais como a Rede Nacional de Saúde Mental e Economia Solidária e o Cadastro de Iniciativas de Inclusão Social pelo Trabalho (CIST).

Nos delineamentos práticos da Rede Nacional, em conformidade com as diretrizes das propostas de articulações entre Ministério da Saúde e MTE, ao longo do ano de 2008 ocorreram Ciclos de Cursos de Capacitação em Incubação de Empreendimentos Solidários da Saúde Mental objetivando a instrumentalização de usuários, familiares e trabalhadores da saúde mental. Ao todo, os Ciclos contemplaram 97 municípios, distribuídos em 24 estados brasileiros (Rede de Saúde Mental e Economia Solidária, 2014). Quanto ao CIST ${ }^{3}$, este foi criado a partir do objetivo de mapear as experiências de geração de trabalho e renda na saúde mental para, com tais dados, ser um instrumento para planejamento e distribuição de incentivos técnico e financeiro para as iniciativas, além de subsidiar ações da política pública, estimulando e fortalecendo as interlocuções entre os grupos cadastrados. Coerente a essas proposições, a partir da instauração do CIST e da Portaria Ministerial n. 1.169/2005 (que destina recursos para municípios que desenvolvem iniciativas de trabalho na saúde mental), desde 2008, chamadas públicas de seleção de projetos para concorrer a apoio financeiro têm exigido em seus procedimentos para candidatura a realização do Cadastro. Nos últimos anos, é exemplo a "Chamada para a Seleção de Projetos de Reabilitação Psicossocial: Trabalho, Cultura e Inclusão Social na Rede de Atenção Psicossocial”, de 2012 e 2013. Dados do CIST dão uma dimensão das ações articuladoras entre trabalho e atenção em saúde mental no território. Informações de 2011 apontam a existência, no Brasil, de 640 iniciativas de geração de trabalho e renda na saúde mental. Os estados com os maiores números de iniciativas são Rio de Janeiro (114 iniciativas) e São Paulo (99) (Ministério da Saúde, 2011).
Os esforços legislativos e organizativos no universo da intersetorialidade entre saúde mental e ECOSOL receberam novas contribuições nos anos de 2010 e 2011, que constituíram os marcos jurídicos da consolidação da saúde mental e ECOSOL, de acordo com Silva (2012). Em 2010, três eventos nacionais foram cenários de discussões e estabelecimento de contribuições para a Política Pública Intersetorial de Saúde Mental e Economia Solidária: a "I Conferência Temática de Cooperativismo Social", a "II Conferência Nacional de Economia Solidária" (CONAES) e a "IV CNSM-Intersetorial".

A I Conferência Temática de Cooperativismo Social, que ocorreu em maio de 2010, teve como tema central "Trabalho e Direitos: Cooperativismo Social como compromisso social, ético e político". As movimentações e efervescências dessa Conferência subsidiaram os outros eventos nacionais daquele ano. A intersetorialidade como palavra de ordem, colocada em diferentes parâmetros e repetida nos três objetivos da Conferência Temática, reverberou nos eventos seguintes. Analiticamente, a partir das informações do Relatório Final da I Conferência, apontamos como positivo o reconhecimento da intersetorialidade do trabalho (colocado no evento através do termo cooperativismo social). Apesar de sua presença na nomenclatura do evento, o conceito cooperativismo social não é esclarecido. O Relatório se dedica a desenhar ou esboçar as fronteiras, limites, e outras informações sobre cooperativismo social. Sem apresentar ou problematizar o conceito, ele é apenas caracterizado como "empreendimentos formados por pessoas em situação de desvantagem por condições físicas, mentais e situações sociais específicas e têm por objetivo promover a inclusão social e econômica dessas pessoas" (Caderno Temático, 2010, p. 10).

Entre as assunções elaboradas a partir do evento, destacamos: a valorização das intersetorialidades, identificada na necessidade de não ignorar as variações de formalidades e informalidades organizativas dos empreendimentos solidários e cooperativos, e da integração e interlocução dos segmentos sociais envolvidos/participantes das iniciativas de trabalho (como citado na Lei do Cooperativismo Social, n. 9.867/1999), evitando microgrupos solitários ou homogêneos no universo total do grupo; a abertura para a necessidade de estudo dos conceitos de rede e cadeia de produção e comercialização na realidade das iniciativas de trabalho, e a aplicação de esforços políticos que favoreçam a sobrevivência financeira dos grupos; entre outros (Caderno Temático, 2010). Desde a I Conferência, quanto às propostas elaboradas que diretamente articulavam processos de trabalho e atenção em saúde 
mental, citamos no eixo "Marco Conceitual" duas importantes sugestões de que se alterassem as acepções de composição do discurso jurídico.

Na primeira delas, há a proposta de modificar a terminologia utilizada desde a Lei do Cooperativismo Social de 1999 quanto às pessoas a serem primordialmente foco de promoção e inclusão social e econômica pelo trabalho. A proposta é pelo abandono da expressão "pessoas em desvantagem", para o privilegio de "pessoas em situação de desvantagem". $\mathrm{O}$ uso da palavra situação valorizaria a transitoriedade que a compreensão dinâmica da vida apresenta e, assim, se propõe que as linhas políticas acompanhem esta existência não fixada.

A segunda proposta de alteração por nós destacada é de que as iniciativas de trabalho na saúde mental se constituam, primordialmente, em contextos distintos dos locais de tratamento. Com isso, busca-se mais uma vez um afastamento da concepção terapêutica do trabalhar, para valorizar a experiência trabalho. Com o abandono da materialidade das arquiteturas físicas do hospital psiquiátrico, se fortalece a produção de sentidos de atenção e cuidado, em que o trabalho é uma estratégia, em detrimento dos objetivos do trabalho para ocupar o tempo livre no contexto asilar.

Apenas um mês após a I Conferência Temática, foi realizada, em Brasília, a II CONAES, com o tema "Pelo direito de produzir e viver em cooperação de maneira sustentável”. Nesta II CONAES, a saúde mental é indiretamente colocada a partir das discussões envolvendo as intersetorialidades da ECOSOL. No evento, a intersetorialidade é reconhecida como oportunidade e desafio para o avanço da economia solidária em termos práticos e políticos. Os delineamentos organizativos, integrativos, legais e financeiros mais uma vez foram discutidos, alimentando anseios e propostas de ação. Destes, citamos nominalmente duas. Uma delas era a de criação de um Sistema Nacional de Políticas Públicas de Economia Solidária que organizaria e implantaria políticas públicas de ECOSOL que articulassem um marco legal (II CONAES, 2010, p. 40). A outra proposta, que preencheu as discussões durante o evento e foi repetida no Relatório Final, era a demanda pela reformulação da Lei n. 9.867/1999, chamada de Lei do Cooperativismo Social. As mudanças solicitadas para a aprovação de uma nova legislação eram de várias frentes, das quais pinçamos duas: a do abandono da dimensão de protegido, em que o trabalho é abarcado na referida Lei, e a da criação de mecanismos de previdência social, para que os participantes das iniciativas de trabalho que recebessem Benefícios de Prestação Continuada (BPC) como proveitos monetários por incapacidade para o trabalho, ou outro benefício social, não tivessem os valores financeiros, fruto do benefício, cancelados.

Entre junho e julho de 2010, foi realizada, em Brasília, a IV CNSM - Intersetorial (2010). Ao longo dos nove anos que separam a III Conferência (ocorrida em 2001 logo após a aprovação da Lei 10.216) da IV Conferência, muitas mudanças referentes ao lugar social da loucura aconteceram, bem como com relação às reflexões teóricas e às experiências práticas de trabalho e renda em contextos institucionais e em espaços comunitários, discussões que permeiam, por exemplo, as atividades do Núcleo de Oficinas e Trabalho (NOT) em Campinas (Souza Queiroz \& Delamuta, 2011), e de projetos de extensão universitária que ofertam assessoria e apoio às iniciativas solidárias (Silva, 2012).

No Relatório Final da III CNSM, a economia solidária foi mencionada uma única vez no eixo de discussões sobre "Direitos e cidadania", quando ela é citada como possibilidade de atuação focada no trabalhar para os serviços substitutivos na comunidade. Curiosamente, a economia solidária não é sequer citada no eixo que diretamente objetivava discutir "Trabalho e geração de renda", que, pelas nossas análises, privilegiava o emprego e o mercado formal de trabalho. Desta forma, a partir das propostas formuladas pela III CNSM, a presença das atividades de trabalho no contexto da saúde mental, no princípio do século XXI, nos leva para a indicação de um processo de normalização (Santiago \& Yasui, 2011). Em um contexto de inserção social, de acesso à cidadania e maior contratualidade social, discussões construídas com a missão de propor diretrizes para a formulação de políticas públicas de saúde mental pautadas pela identificação entre atividades de trabalho - inserção formal no mercado de trabalho via emprego são suporte de processos de transferências da segregação social, da instituição manicomial para a alienação subjetiva do mercado formal de trabalho, sendo que este último se preocupa com as necessidades do próprio mercado e não propriamente com as do trabalhador. Na IV CNSM-I, também podem ser localizadas preocupações com a inclusão e reinserção no mercado formal de trabalho (mais diminuídas quando comparadas às da III Conferência). Há ainda duas propostas da IV Conferência que consideramos mais detalhadamente. Discussões realizadas na Conferência apresentam como recomendação a construção de mecanismos de acompanhamento para a inserção no mercado de trabalho formal de usuários da saúde mental participantes de projetos de inclusão social pelo trabalho no contexto da saúde mental. Esses mecanismos deveriam estar previstos nos projetos terapêuticos dos sujeitos e em acordo com a política nacional de saúde mental, assim como com a de ECOSOL. Em um subeixo chamado "Inserção no mercado formal de trabalho", 
é reafirmada (visto que já estava presente na III CNSM) a proposição de criação de uma legislação específica de cotas de trabalho em empresas públicas e privadas para os sujeitos atendidos por serviços de saúde mental.

A multiplicidade de proposições, de enfrentamentos da realidade cotidiana do cuidado em saúde mental e de articulações possíveis, desejadas e articuladas que a IV CNSM produziu no campo das relações entre o trabalhar e a atenção em saúde mental, é significativa. Mas algumas preocupações merecem ser apontadas, como agora fazemos.

O mercado formal de trabalho, via emprego formal, está posto enquanto objetivo a ser almejado para as atividades de trabalho na saúde mental. O evento da IV Conferência nomeia um subeixo ("Inserção no mercado de trabalho"), que é componente do eixo "Trabalho, geração de renda e economia solidária". Parece-nos contraditório que um evento de temática intersetorial marque repetidamente o mercado formal como finalidade de processos. Mesmo que se argumente a existência de diversidade no mercado formal de trabalho, ainda assim ele é objetivo final de diversas propostas, como a da criação de legislação de cotas de trabalho aos atendidos pela saúde mental em espaços públicos e privados, a flexibilização de cargas e funções de trabalho aos usuários dos serviços de saúde mental, inclusive com criação de postos de trabalho flexibilizados, e desenvolvimento de estratégias de maior inclusão no mercado formal de trabalho aos que participarem dos programas de reabilitação produtiva e trabalho protegido. São processos de homogeneização de heterogêneas formas de ser, de trabalhar, de se inserir em um projeto ou iniciativa de trabalho e mesmo de se inserir e estar no mercado de trabalho, via emprego formal. Também são processos de apagamentos das diferenças com estabelecimento de diretividade nas propostas de implantação e administração das ações e atividades de trabalho na saúde mental, inclusive dos serviços abertos. Dessa forma, reconhecemos e respeitamos o mercado formal de trabalho como mais um campo de inserção e realização de trabalho quando do desejo dos usuários da saúde mental, porém a garantia deste acesso, que é um direito, deve ser acompanhada de constante problematização quanto as suas possibilidades de inventividade do trabalhar, em um processo de que deve ser de inserção no mercado formal de trabalho, e não de adequação ao mesmo.

A partir de alguns estudos foucaultianos sobre governamentalidade e biopolítica (Foucault, 1986; 2008a), afirmamos serem essas propostas para a formulação de políticas que, ao invés de promoverem aquilo a que se pretendem (inclusão pelo trabalho, reinserção social), promovemuma inclusão-excludente, em que as prerrogativas de espaços diferenciados e ações protegidas, ao invés de valorizar a diversidade, colocam em relevo a diferença. Nesse sentido, a política produz exóticos, estranhos no contexto de trabalho formal e do mercado, reforçando a normalidade como adequação às normas estabelecidas. A participação no mercado formal de trabalho parece ser almejada como um importante parâmetro de inclusão social. Se o mercado formal, via emprego, é foco, como ficam as dimensões éticas, estéticas, econômicas e autogestionárias que a ECOSOL promove e fortalece? Sabemos ser o mercado muito dogmático quanto às exigências normalizantes de conduta que são impostas aos seus envolvidos. Constituído no âmbito da norma, a participação no mercado de trabalho pelo emprego formal é tida como natural e os que anseiam por ele e se dedicam a dele participarem vivenciam um processo naturalizado de contato com uma matriz de inteligibilidade que configura mercado e emprego formais, em que a promessa é de que os laços e as relações fazem sentido acima de tudo. Dessa forma, ansiar para que esse mercado formal de trabalho se adeque ao sujeito que nele se envolve a partir das propostas acima elencadas é ancorar o processo em uma ingenuidade. Assim, defendemos que o mercado formal de trabalho seja parte do processo de relações construídas na experimentação dos sujeitos em suas relações trabalho-saúde mental, e não finalidade. Como parte do processo, no estar ou trocar com o mercado formal de trabalho, abandona-se o regime de verdade de que toda inclusão social possível (inclusão social pelo trabalho ou não) seja uma inclusão social no mercado dominante. Outro aspecto do processo de dimensionar o mercado como parte e não como fim é de que se superam as prerrogativas de que a inclusão se faz pelo ser igual aos demais, quando, na verdade, toda igualdade é apagadora das diferenças, é normalizante.

Observa-se, nas páginas do Relatório da IV Conferência (assim como no relatório da III Conferência), o uso de variados conceitos sem maiores definições. Inclusão social pelo trabalho, trabalho e geração de renda, (re)inserção social e reabilitação psicossocial são indiscriminadamente utilizados, muitas vezes como sinônimos. Como conceitos polissêmicos que fazem presença nos discursos histórico, jurídico, social e cotidiano dos equipamentos de saúde, o uso deles sem definições ou estabelecimentos de suas fronteiras e sobreposições promove uma confusão semântica que pode fomentar ações práticas inconsistentes e pouco fundamentadas tecnicamente.

Em dezembro de 2011, o "II Encontro Nacional de Experiências de Geração de Trabalho e Renda da Saúde Mental", realizado no Rio de Janeiro, ainda 
recebia subsídios dos eventos anteriores. O II Encontro teve por objetivo debater sobre o cenário atual da Rede Brasileira de Saúde Mental e Economia Solidária, assim como apresentar propostas para um Programa Nacional de Apoio ao Cooperativismo Social a ser lançado (Lei $\mathrm{n}^{\circ}$ 12690/2012). O evento propiciou um espaço de trocas e organização das sugestões e reinvindicações que logo, em seguida, em 2012, iriam integrar uma Campanha pela Lei da Economia Solidária, que hoje está em curso com a tramitação do Projeto de Lei n. 4685, que propõe a criação do Sistema Nacional de Economia Solidária, desde 2012.

\section{Considerações finais: a produção do presente}

No Brasil, a ECOSOL surgiu como estratégia a partir de movimentações, resistências e lutas sociais contra o desemprego, a pobreza e a precariedade social da vida, fenômenos produzidos pela lógica devastadora do capital. Primando pelo trabalho autogestionário e coletivo que produz riqueza, solidariedade e desenvolvimento econômico e social, a economia solidária se tornou política pública brasileira a partir de 2003. Os movimentos da ECOSOL e da Reforma Psiquiátrica brasileira apresentam a mesma matriz de configuração de forças sociais e políticas para construir outros modos de trabalhar e viver em uma sociedade mais justa, inclusiva e generosa quanto às diversidades, fazendo sentido as aproximações e as trocas que os movimentos realizaram nas últimas décadas, especialmente com as proposições de inclusão social pelo trabalho no contexto de atenção em saúde mental.

Desde os anos de 1990, pontes políticas começaram a ser estabelecidas entre a saúde mental e a ECOSOL, intensificando-se depois de 2001. Nos anos seguintes, eventos isolados de cada área e eventos articulados fomentaram a proposição da saúde mental e ECOSOL como política pública brasileira intersetorial. Cartografias dessa articulação registrada em instrumentos legais e políticos, com o objetivo de identificar e problematizar os conceitos, as preocupações, as estratégias e os desafios presentes e ausentes, permitem alguns apontamentos. Compreendemos que um questionamento se coloca quando do desafio de construir e efetivar uma política pública de inclusão social pelo trabalho pelo viés da ECOSOL no contexto da saúde mental: o trabalho é ponto de partida ou de chegada? Pensar de onde se parte e aonde se objetiva chegar é a oportunidade de valorizar analiticamente uma das questões que abarcamos ao longo desta tese: a conceituação de trabalho que está permeando discursivamente a política, e que irá fundamentar as ações práticas.
As políticas públicas diretamente se ligam ao conceito de cidadania ao regulamentarem os direitos dos indivíduos, tendo por gênese a Constituição Federal. Sendo que esta, como carta máxima, determina as competências do Estado, sendo a referência legal para elaboração, execução e avaliação das políticas públicas. Assim, políticas públicas e ações do Estado são partes do mesmo projeto de construção que um país pretende realizar. No caso da ECOSOL, o Estado brasileiro, nas últimas décadas, tem buscado sua localização, estrategicamente, no escopo das políticas públicas de desenvolvimento, identificando sua potencialidade para criar e articular ações integradas e articuladas de forma emancipatória. Como política de desenvolvimento, seus objetivos finais se afastariam de demandas assistenciais e compensatórias, restringindo-se a serem apenas alavancas iniciais (Schwengber, $\mathrm{s} / \mathrm{d}$ ).

O Estado brasileiro, ao articular, via política pública, saúde mental e ECOSOL, tem objetivado investir no reconhecimento de novos sujeitos sociais, novos direitos de cidadania e novas formas de produção de bens e relações. Inicialmente, como política de Governo, nos últimos anos os esforços têm sido para que se torne uma política de Estado. A política pública brasileira de saúde mental e ECOSOL é historicamente muito recente, o que significa que o objetivo de uma intersetorialidade está em processo, apesar disso, identificamos que ela é oportunidade objetiva e efetiva de inclusão social pela via do trabalho.

Na modernidade, o Estado ganhou visibilidade como centralizador e propagador de relações de poder, que é uma percepção enganosa. Baseados em Foucault (1986), assumimos a compreensão de que o poder capilarmente passeia, enraizando-se pelo social, em um processo de engendramento de grande força que opera pela onipresença e microfísica. Como estratégia de conduta de si e de outros, o Estado constituirá ações de governamento que darão materialidade ao poder através do que efetivamente faz, mas também pelo que se omite.

O governamento da vida é função suprema do Estado e exige "utilizar mais táticas do que leis, ou utilizar ao máximo as leis como táticas" (Foucault, 1986, p. 284). O homem, objeto das Ciências Humanas, é foco do projeto de racionalização da política estatal na modernidade. A intervenção do Estado nas diversas questões sociais se justificaria pelo argumento da manutenção do bem-estar dos indivíduos e da sociedade, em uma sociabilidade autoritária travestida de proteção e justiça social, de que o sistema jurídico das leis e as políticas públicas seriam parte crucial. A medida da justiça social seria a normalidade, sendo esta a capacidade de adequação a normas apresentadas. 
A partir de então, o problema da definição do conceito de justiça social passa a ser o de saber se é possível existir uma regra sobre a qual se possa chegar a um acordo e permitir a cada um medir-se em relação ao outro. (Macedo, 1990, p. 8)

A norma permite delinear a igualdade e a desigualdade, a inclusão e a exclusão e, de forma insensível e fictícia, estabelecer a medida para que cada um pense seu valor social e sua identidade como parte da coletividade. Na biopolítica, todo governamento é dirigido à população, em exercícios de governamentabilidade. Dessa forma, as políticas públicas podem ser entendidas como exemplos de visibilidade das ações de governamentabilidade que o Estado moderno promove a partir dos objetivos de gerir condutas humanas com o mínimo de poder empregado e o máximo resultado almejado. No campo recente da saúde mental, nas últimas décadas uma rede sutil de objetivações e subjetivações tem difundido efeitos normalizantes diversificados em condutas cotidianas, voltando-se para o campo social com marcações includentes mais sofisticadas biopoliticamente, como as proposições de reinserção social e inclusão social pelo trabalho, desde os anos de 1990, nas experiências e legislações brasileiras. Em operações de décadas anteriores, a captura tinha o objetivo de tirar do convívio os indesejáveis, pela "reclusão da exclusão". Recentemente, o objetivo da inclusão é para normalizá-los, fixando os indivíduos a aparelhos de reprodução, em processos de "reclusão de normalização" (Foucault, 1996). Na modernidade, a inclusão é a dimensão maior, mas sem apagar a exclusão em seus desdobramentos de racionalidade. Por isso falarmos em um binômio inclusão-exclusão.

Com base nos apontamentos aqui apresentados e em suas interlocuções com as cartografias feitas sobre a saúde mental e a ECOSOL como estratégias da atual política brasileira de saúde mental, afirmamos que a importância alcançada pela ECOSOL nos espaços teóricos e práticos da saúde mental pode ser atribuída ao fato de, conjuntamente, elas se fortalecerem como alternativas possíveis às formas antes hegemônicas: para a ECOSOL, a desconstrução da lógica produtivista e alienada como única relação possível no mundo do trabalho; para a saúde mental, a oportunidade de arquitetar a inclusão social de sujeitos com vivências de sofrimento psíquico para além de espaços e ações de trabalho terapêuticos, de ocupação do tempo livre, cerceados e protegidos, ou seja, de inserção social artificial. Apesar de seu ideário diferencial, na intersetorialidade saúde mental - ECOSOL se nota a existência de um campo heterogêneo de discursos que por vezes evidenciam falta de consistência da amplitude almejada pelas proposições feitas, bem como pela concepção dos alvos e objetos de críticas. Destacamse dois conjuntos de matrizes que apresentam falta de conformidade interna em seu conteúdo: a presença e as discussões quanto às perspectivas do mercado formal de trabalho via emprego e os elementos conceituais referentes ao trabalho.

A discursividade das produções políticas sobre saúde mental - ECOSOL tem repetidamente incluído o mercado formal de trabalho como espaço almejado de (re)inserção social pelo formato do emprego. Em exposições diretas e em entrelinhas propositivas, o sentido produzido por esses discursos é de um trabalhar pautado por uma linearidade adaptativa aplicada aos usuários da rede de saúde mental. Linearidade sustentada por dualismos de valor e contra-valor existencial e identitário (louco - são, capaz - incapaz), que são historicamente resgatados dos discursos manicomiais do trabalho curativo e, ao mesmo tempo, são de parâmetro de normalidade, mas agora localizado na tutela do mercado formal de trabalho via emprego, e não mais na segregação institucional dos hospícios do passado.

Trata-se de uma divergência que evidencia o binômio inclusão - exclusão da estratégia de governamentabilização do Estado, que administra a si mesma, ao mesmo tempo que se alimenta através de indicativos de resolutividade das políticas públicas, mostrando que a dinâmica de investir na população é investir no próprio Estado. Nesse sentido, com o ainda foco no emprego formal, a política pública de saúde mental e a ECOSOL perigosamente flertam com a lógica capitalista de produção e reprodução de bens e relações, que com preponderância transforma os elementos presentes no processo em mercadorias, inclusive o trabalho humano. $\mathrm{Na}$ política, são frágeis as propostas de construção de estratégias concretas de enfrentamento e desconstrução dessa dinâmica destrutiva do modo capitalista quando do envolvimento dos sujeitos trabalhadores usuários da rede de saúde mental. Não são feitas denúncias nem é assumido pelo discurso politico-legal que as oportunidades no mercado formal de trabalho por vezes são poucos factíveis, mas ações inclusivas objetivadas por racionalidades capitalistas que muito se afastam dos sentidos da ECOSOL. Exceções têm ocorrido em experiências práticas que contribuem para a geração de trabalho e renda em espaços diversos, como também no mercado formal de trabalho. São experiências como as Incubadoras Universitárias (para apenas um exemplo, citamos a da Universidade Estadual de Maringá, no Paraná), o Núcleo de Oficinas e Trabalho (NOT), ligado ao Serviço de Saúde Dr. Cândido Ferreira (Campinas - SP), o Núcleo de 
Saúde Mental e Trabalho (NUSAMT), projeto ligado à Superintendência de Saúde do Estado do Rio de Janeiro.

Defendemos que o trabalho e a participação no mercado de trabalho via emprego não devem ser compreendidos como respostas a necessidades normalizantes ("sou trabalhador, o registro comprova!"), mas sim como campo de oportunidade de produção de sentidos, de valores subjetivos e de valores de troca. E essa concepção, ampliada e necessária, deve se fazer presente nas propostas das políticas públicas. Em outras palavras, desconstruir a hegemonia do emprego e do mercado formal quando se articula e se vivencia o trabalho e o trabalhar é estranhar e desconstruir a governamentabilidade capitalista. Em contrapartida, reforçar o operador empreguista é dar manutenção a ela.

A análise dos discursos que permeiam as atividades de trabalho em termos de seus enunciados visíveis evidencia uma pulverização de conceituações que não são exploradas, mas estão em um mosaico de terminologias por vezes contraditórias. Não desejávamos localizar uma unidade conceitual ou, na constatação de sua ausência, que uma fosse construída, como em uma pacificação teórica. O que colocamos em jogo é que a falta de delineamento das enunciações constituídas como linhas mestras nos documentos que abarcam a relação entre loucura e trabalho favorece uma miscelânea teórica e prática em que se não se define do que falamos e fazemos, qualquer coisa pode ser algo. Apontamos a necessidade urgente de que sejam feitas discussões dos conceitos e dos contornos teóricos a partir dos quais os discursos serão proferidos. O espaço dos fóruns e das conferências políticas poderiam ser opções possíveis ao reunirem gestores, trabalhadores e usuários da saúde mental, bem como estudiosos da área e acadêmicos.

Concluímos, indicando alguns pontos ainda carentes de propulsão por meio de políticas públicas que construam instrumentos e mecanismos contribuintes com o reconhecimento e o fomento da intersetorialidade saúde mental - ECOSOL. São proposições de suporte mais concretos de consolidação das mudanças realizadas e enfrentamento de novos desafios, tais como parâmetros mais claros de intersecção com políticas assistenciais e compensatórias, estabelecimento de articulações do poder público com a sociedade civil para criar e executar as políticas, edificação de mecanismos mais amplos e sustentáveis.

Outras discussões ainda são necessárias, mas elas ultrapassam os objetivos deste texto que foram os de cartografar, mediante documentos, os discursos políticos do enlace entre saúde mental e economia solidária. Destas outras discussões, são urgentes as problematizações do cotidiano e experiências práticas construídas e afetadas por esses discursos que aqui traçamos. Dentre os pontos que carecem de investigação, citamos: como a política pública repercute na vida das pessoas? Que organização social e subjetiva ela tem efetivamente produzido? Qual o valor de saúde que as experiências práticas têm produzido? Que suportes institucionais, teóricos e práticos têm sido oferecidos aos trabalhadores da saúde mental? São suficientes?

Enquanto política pública, a composição da saúde mental com a economia solidária tem recentemente ganhado maior espaço e concretude legal, política e prática, destacando-se ao valorizar o trabalho e o trabalhar como possibilidade de estar no social de forma mais integral que as simplificadas e insuficientes relações utilitárias e normalizantes que o capitalismo investe. Os conflitos e as contradições são parte do debate público e dos processos aqui cartografados e demonstram que existe vida política ativa nos grupos que estão construindo essas histórias.

\section{Notas}

Algumas destas iniciativas de apoio foram: Movimento dos Sem Terra (MST), Associação Nacional dos Trabalhadores de Empresas em Auto-Gestão (ANTEAG), Rede Universitária de Incubadoras Tecnológicas de Cooperativas Populares (ITCPs), UNITRABALHO.

2 Somente um mês após a criação da SENAES, Paul Singer assumiu sua coordenação, estando nela até os dias de hoje. Como um dos maiores nomes atuais na área e destacado histórico de participações em movimentos sociais e políticos, sua presença em tal posição reflete o empenho oficial genuíno na construção de outras relações e processos de trabalho.

3 Localizada no seguinte endereço: http://formsus.datasus. gov.br/site/formulario.php?id aplicacao $=865$.

\section{Referências}

Amarante, P. (2000). Loucos pela vida: a trajetória da reforma psiquiátrica no Brasil. Rio de Janeiro: Panorama/ENSP.

Barbosa, R. N. C. (2007). A economia solidária como política pública: uma tendência de geração de renda e ressignificação do trabalho no Brasil. São Paulo: Cortez.

Caderno Temático. (2010). I Conferência temática de cooperativismo social. Acesso em 28 fevereiro. 2014, em http://portal.mte.gov.br/data/files/8A7C812D36A28000013 731C1E94D5DBD/cad tematico cooperativismo.pdf.

II CONAES - II Conferência nacional de economia solidária. (2010). Pelo direito de produzir e viver em cooperação de maneira sustentável. Acesso em 27 abril, 2014, em http:// www.ipea.gov.br/participacao/images/pdfs/conferencias/ Economia_Solidaria_II/deliberacoes 2 _conferencia economia_solidaria.pdf.

IV CNSMI - IV Conferência Nacional de Saúde Mental Intersetorial. (2010). Relatório Final. Acesso em 27 de abril, 
2014, em http://conselho.saude.gov.br/biblioteca/Relatorios/ relatorio_final_IVcnsmi_cns.pdf

Foucault, M. (1986). Microfisica do poder (6 $6^{\mathrm{a}}$ ed.). Rio de Janeiro: Graal.

Foucault, M. (2006). A verdade e as formas jurídicas. Rio de Janeiro: Nau.

Foucault, M. (2008a). Nascimento da biopolitica. São Paulo: Martins Fontes.

Foucault, M. (2008b). Segurança, território, população. São Paulo: Martins Fontes.

Lei n. 9.867, de 10 de novembro de 1999. (1999). Dispõe sobre a criação e o funcionamento de Cooperativas Sociais, visando à integração social dos cidadãos. Acesso em 12 de março, 2015, em https://www.google.com.br/search?q=Lei + n. +9.8 $\underline{67 \& \text { oq }=\text { Lei }+ \text { n. }+9.867 \& \text { aqs }=\text { chrome. } .69 i 57 j 69 i 59.916 j 0 j 7 \&}$ sourceid $=$ chrome\&es sm $=122 \&$ ie $=U T F-8$

Lei n. 12.690, de julho de 2012. (2012). Dispõe sobre a organização e o funcionamento das Cooperativas de Trabalho; institui o Programa Nacional de Fomento às Cooperativas de Trabalho - PRONACOOP; e revoga o parágrafo único do art. 442 da Consolidação das Leis do Trabalho - CLT, aprovada pelo Decreto-Lei oㅜ 5.452, de 1o de maio de 1943 . Acesso em 27 abr. 2014, em http://www.planalto.gov.br/ ccivil_03/_Ato2011-2014/2012/Lei/L12690.htm

Lima, I. B., Silva, J. E., Falchetti, C. A., \& Cruz, S. S. (2013). Políticas públicas de saúde mental e economia solidária: construção de uma nova concepção. Revista de enfermagem, 7, 1008-1015. Acesso em 27 de abril, 2014, em http://www. revista.ufpe.br/revistaenfermagem/index.php/revista/article/ view/3526.

Macedo, R. P. (1990). Foucault: o poder e o direito. Tempo Social. Rev. Sociol. USP, 2(1), 151-176.

Ministério da Saúde. SAS/DAPES. (2011). Saúde Mental em Dados, 9, ano VI. Informativo eletrônico. Brasília, DF: Autor. Acesso em 27 abril, 2014, em http://docslide.com.br/ documents/09saude-mental-em-dados-julho-2011.html

Portaria Interministerial n. 353, de 07 de março de 2005. (2005). Institui o Grupo de Trabalho de Saúde Mental e Economia Solidária e dá outras providências. Acesso em 27 de abril, 2014, em http://www.fenix.org.br/ PORTARIAINTERMINISTERIAL353-marco-2005.pdf

Projeto de Lei n. 4685, de 08 de novembro 2012. (2012). Dispõe sobre a Política Nacional de Economia Solidária e os empreendimentos econômicos solidários, cria o Sistema Nacional de Economia Solidária e dá outras providências. Brasília, DF: Congresso Nacional.

Rede de Saúde Mental e Economia Solidária. (2014). Acesso em 06 de julho, 2015, em https://saudeecosol.wordpress. com/tag/ministerio-da-saude/.

Rolnik, S. (1989). Cartografia sentimental: transformações contemporâneas do desejo. São Paulo: Estação Liberdade.

Santiago, E. \& Yasui, S. E. (2011). O trabalho como dispositivo de atenção em saúde mental. Revista de Psicologia da UNESP, 10(1), 195-210. Acesso em 26 de abril, 2014, em http://www2.assis.unesp.br/revpsico/index.php/revista/ article/view/191/246

Santiago, E. \& Yasui, S. (2013). De direito social a dispositivo de saúde: o trabalho na legislação de saúde vigente. Revista Psicologia e Saúde, 5(2), 81-91. Acesso em 12 de março, 2015, em http://pepsic.bvsalud.org/scielo.php?pid=S2177093X2013000200003\&script $=$ sci arttext

Saraceno, B. (2001). Libertando identidades: da reabilitação psicossocial à cidadania possível. Belo Horizonte: Te Corá; Rio de Janeiro: Instituto Franco Basaglia.

Schwengber, A. (s/d). Diretrizes para uma política pública de economia solidária no Brasil: a contribuição da rede de gestores. Acesso em 27 abril, 2014, em http://portal.mte.gov. br/data/files/FF8080812BCB2790012BCF1A3B9329B0/ conf rede.pdf

Silva, A. L. A. (2012). A construção de um projeto de extensão universitária no contexto das políticas públicas: saúde mental e economia solidária. Tese de Livre Docência, Escola de Enfermagem, Universidade de São Paulo. Acesso em 12 de março 2015, em http://www.teses.usp.br/teses/ disponiveis/livredocencia/7/tde-23112012-092937/pt-br.php

Singer, P. (2002). Introdução à economia solidária. São Paulo: Perseu Abramo.

Souza Queiroz, M. \& Delamuta, L. A. (2011). Saúde mental e trabalho interdisciplinar: a experiência do "Cândido Ferreira” em Campinas. Ciência \& Saúde Coletiva, 16(8), 3603-3612.

Submissão em: 27/04/2014

Revisão em: 02/03/2015

Aceite em: 28/03/2015

Eneida Santiago é mestre em Psicologia e Sociedade e doutora em Subjetividade e Saúde Coletiva pela

Unesp-Assis. Atualmente é professora adjunta da UEL

- Universidade Estadual de Londrina, no Departamento de Psicologia Social e Institucional. Endereço para

correspondência: Universidade Estadual de Londrina. Departamento de Psicologia Social e Institucional. Rodovia Celso Garcia Cid (PR 445), Km 380. Londrina/ PR. Caixa Postal 10.011 CEP 86.057-970

E-mail: ensantiagobr@yahoo.com.br

Silvio Yasui é mestre em Psicologia pela Universidade Estadual Paulista Júlio de Mesquita Filho e doutor em Saúde Pública pela Fundação Oswaldo Cruz. Atualmente é professor assistente doutor da Universidade Estadual Paulista Júlio de Mesquita Filho - Campus Assis. Assis/SP. E-mail: silvioyasui@gmail.com 